\title{
Evaluation of Clinical Manifestations in Patients with Severe Lymphedema with and without CCBE1 Mutations
}

\author{
M. Alders ${ }^{a} \quad$ A. Mendola ${ }^{b} \quad$ L. Adès ${ }^{c} \quad$ L. Al Gazalid $\quad$ C. Bellini ${ }^{\mathrm{e}} \quad$ B. Dallapiccola ${ }^{f} \quad$ P. Edery ${ }^{g, h}$

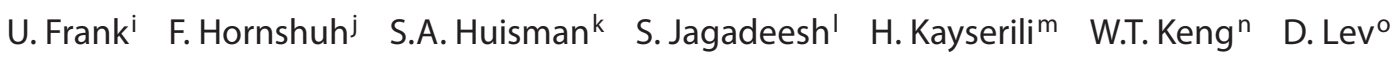 \\ C.E. Prada ${ }^{p} \quad$ J.R. Sampson ${ }^{q} \quad$ J.Schmidtke ${ }^{r} \quad$ V. Shashi ${ }^{\mathrm{s}} \quad$ Y. van Bever ${ }^{\mathrm{t}} \quad$ N. Van der Aa ${ }^{\mathrm{u}}$ \\ J.M. Verhagen ${ }^{t}$ J.B. Verheij ${ }^{v}$ M. Vikkulab,x R.C. Hennekam ${ }^{w}$
}

a Department of Clinical Genetics, Academic Medical Centre, University of Amsterdam, Amsterdam, The Netherlands; ${ }^{\mathrm{b}}$ Lab of Human Molecular Genetics, de Duve Institute, Université catholique de Louvain, Brussels,

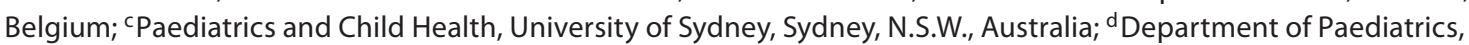

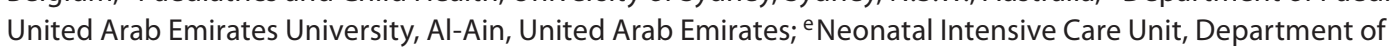
Paediatrics, Gaslini Institute, University of Genoa, Genoa, and ${ }^{f}$ Ospedale Pediatrico Bambino Gesù, IRCCS, Rome, Italy; ${ }^{9}$ Hospices Civils de Lyon, Service de Cytogénétique Constitutionnelle, Bron, and h Université Lyon 1, Inserm U1028, CNRS UMR5292, CRNL, TIGER, Lyon, France; 'Sozialpädiatrisches Zentrum, Braunschweig, and 'Department of Neonatology and Pediatrics Intensive Care, Vest. Children's Hospital Datteln, University Witten/Herdecke, Witten, Germany; ${ }^{\text {K} P r i n s e n s t i c h t i n g, ~ C e n t r e ~ f o r ~ P e o p l e ~ w i t h ~ I n t e l l e c t u a l ~ D i s a b i l i t i e s, ~ P u r m e r e n d, ~ T h e ~ N e t h e r l a n d s ; ~}$

'Genetic Counselling Department, Foetal Care Research, Chennai, India; ${ }^{\mathrm{m}}$ Medical Genetics Department, Istanbul Medical Faculty, Istanbul University, Istanbul, Turkey; ${ }^{n}$ Department of Genetics, Kuala Lumpur Hospital, Kuala Lumpur, Malaysia; ${ }^{\circ}$ Institute of Medical Genetics, Wolfson Medical Center, Holon, Israel; P Division of Human Genetics, Cincinnati Children's Hospital Medical Center, Cincinnati, Ohio, USA; ${ }^{9}$ Institute of Medical Genetics, Cardiff, UK; 'r Institut für Humangenetik, Medizinische Hochschule Hannover, Hannover, Germany; ${ }^{\mathrm{s}}$ Division of Medical Genetics, Duke University, Durham, N.C., USA; ${ }^{\mathrm{t} D e p a r t m e n t ~ o f ~ C l i n i c a l ~ G e n e t i c s, ~ E r a s m u s ~ M e d i c a l ~ C e n t r e, ~}$ Rotterdam, The Netherlands; " Department of Medical Genetics, University Hospital and University of Antwerp, Antwerp, Belgium; v Department of Genetics, University Medical Centre Groningen, Groningen, and wDepartment of Paediatrics, Academic Medical Centre, University of Amsterdam, Amsterdam, The Netherlands; ×WELBIO-Walloon Excellence in Lifesciences and Biotechnology, de Duve Institute, Université catholique de Louvain, Brussels, Belgium

\section{Key Words}

Autosomal recessive $\cdot$ CCBE1 $\cdot$ Genotype-phenotype $\cdot$ Hennekam syndrome $\cdot$ Lymphangiectasia $\cdot$ Lymphatic dysplasia $\cdot$ Lymphedema

\section{Abstract \\ The lymphedema-lymphangiectasia-intellectual disability (Hennekam) syndrome (HS) is characterised by a widespread congenital lymph vessel dysplasia manifesting as congenital}

lymphedema of the limbs and intestinal lymphangiectasia, accompanied by unusual facial morphology, variable intellectual disabilities and infrequently malformations. The syndrome is heterogeneous as mutations in the gene CCBE1 have been found responsible for the syndrome in only a subset of patients. We investigated whether it would be possible to predict the presence of a CCBE1 mutation based on phenotype by collecting clinical data of patients diagnosed with $\mathrm{HS}$, with or without a CCBE1 mutation. We report here the results of 13 CCBE1 positive patients, 16 CCBE1 negative pa-

\section{KARGER}

E-Mail karger@karger.com

www.karger.com/msy
(C) 2012 S. Karger AG, Basel

1661-8769/13/0043-0107\$38.00/0
Dr. R.C. Hennekam

Department of Paediatrics, Room H7-236, AMC

Meibergdreef 9

NL-1105 AZ Amsterdam (The Netherlands)

Tel. +31 205668 844, E-Mail r.c.hennekam@amc.nl 
tients, who were clinically found to have classical HS, and 8 patients in whom the diagnosis was considered possible, but not certain, and in whom no CCBE1 mutation was identified. We found no statistically significant phenotypic differences between the 2 groups with the clinical HS phenotype, although the degree of lymphatic dysplasia tended to be more pronounced in the mutation positive group. We also screened 158 patients with less widespread and less pronounced forms of lymphatic dysplasia for CCBE1 mutations, and no mutation was detected in this group. Our results suggest that (1) CCBE1 mutations are present only in patients with a likely clinical diagnosis of $\mathrm{HS}$, and not in patients with less marked forms of lymphatic dysplasia, and (2) that there are no major phenotypic differences between HS patients with or without CCBE1 mutations.

Copyright $\odot 2012$ S. Karger AG, Basel

Lymphedema is in most patients a secondary phenomenon and caused by external factors such as infection, trauma, surgery, or radiation. In at least $10 \%$ of patients, lymphedema is a primary and heritable condition caused by defects in the design or development of lymph vessels. To date, only a limited number of genes are known to be involved in heritable lymphedema syndromes. Congenital isolated lymphedema can be caused by mutations in the lymphatic specific growth factor VEGFC receptor VEGFR3 [Irrthum et al., 2000; Karkkainen et al., 2000], and sometimes the lymphedema in patients with mutations in GJC2 is congenital [Ferrell et al., 2010, Ostergaard et al., 2011]. Congenital lymphedema is frequently syndromic, and causative genes have been found for thelymphedema-distichiasis syndrome (FOXC2), hypotrichosislymphedema-telangiectasia syndrome (SOX18), incontinentia pigmenti (IKBKG), Noonan syndrome (PTPN11 and other RAS-MAPK pathway genes), congenital disorder of glycosylation type 1a (PMM2), and the choanal atresia and lymphedema syndrome (PTPN14) [Van Schaftingen and Jaeken, 1995; Fang et al., 2000; Döffinger et al., 2001; Tartaglia et al., 2001; Irrthum et al., 2003; Au et al., 2010]. Mutations in VEGFR3 have also been found in a patient with congenital lymphedema, unusual facial morphology and distal limb defects [Ghalamkarpour et al., 2009], which may indicate that some patients designated to have isolated lymphedema may in fact have a syndromic form. Many syndromic forms are known for which the causative gene(s) have not been identified yet [Hennekam et al., 2010].

Recently, mutations in $C C B E 1$ were shown to cause a generalised form of syndromic lymphatic dysplasia [Alders et al., 2009; Connell et al., 2010]. This syndrome was first described in 1989 [Hennekam et al., 1989] in a highly inbred family with 3 affected children who had generalised lymphedema predominantly in limbs, intestinal lymphangiectasia, distinctive facial features, and variable intellectual disabilities. Since then about 30 patients with this lymphedema-lymphangiectasia-intellectual disability or Hennekam syndrome (HS) have been reported [Van Balkom et al., 2002].

The CCBE1 gene is a putative extracellular matrix protein and crucial for lymphatic development in zebrafish [Hogan et al., 2009]. Mutations in CCBE1 were detected in only a subset (23\%) of patients clinically diagnosed with HS suggesting genetic heterogeneity [Alders et al., 2009]. Here we report on the results of molecular analysis in a series of HS patients and a series of patients with clinically less marked lymphatic dysplasia, and the analysis of the phenotype of HS patients with and without CCBE1 mutations, to investigate whether a correlation between clinical phenotype and presence of CCBE1 mutation can be established.

\section{Methods}

Between 01.01.2000 and 01.01.2011, 51 patients were referred to the diagnostic lab of the Academic Medical Center in Amsterdam for molecular studies. A questionnaire asking detailed information about the clinical phenotype was sent to all referring physicians. In all patients, except one (patient 12), clinical photographs were available which were evaluated along with the questionnaire data by a single observer (R.C.H.). Statistical analysis of the data was done using the two-tailed Fisher's exact test. p values for comparison of developmental delay in the various subgroups were also calculated keeping the different subcategories (normal, B, DD, sDD, and GMD). p values $<0.05$ are considered clinically significant.

In addition, samples of 158 patients with less marked forms of lymphatic dysplasia were screened for mutations in CCBE1. These patients had been referred for molecular analysis of VEGFR3, FOXC2 and SOX18, and none had mutations in these genes.

Mutation analysis of CCBE1 was performed by PCR amplification of all coding exons followed by bidirectional sequencing using the BigDye kit v1.1 (Applied Biosystems) and an ABI3700 genetic analyzer (Applied Biosystems), or by high resolution melting (HRM)-based screening (Light Cycler, Roche) combined with bidirectional sequencing on CEQ2000 capillary sequencer (Beckman Coulter). Sequence results were analyzed using CodonCode aligner (CodonCode Corporation) or Sequencher ${ }^{\mathrm{TM}} 4.5$ software.

\section{Results}

In total, 34 (67\%) of the questionnaires were returned. The major clinical data are summarised in table 1 and illustrated in figure 1 . Of 2 mutation positive patients (4 and 5), no questionnaire was returned, and clinical data 

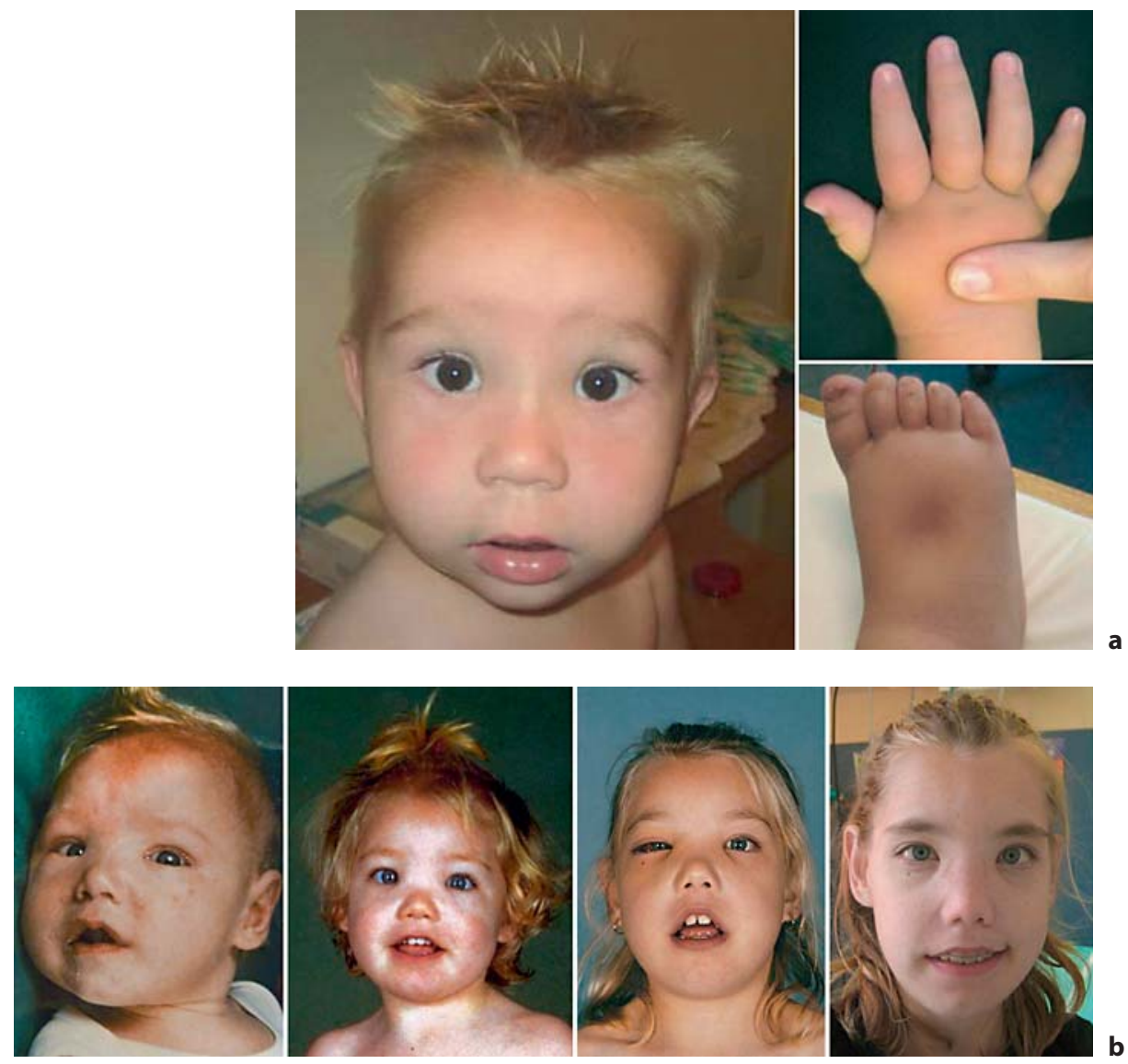

Fig. 1. a Phenotype of patient 10 with a $C C B E 1$ mutation at age 2 years showing hair whorl in anterior hairline, hypertelorism, thick lateral eyebrows, epicanthi, depressed nasal bridge, and (pitting) lymphedema of distal limbs. $\mathbf{b}$ Changes in facial phenotype and lower limbs lymphedema in patient 11 with a CCBE1 mutation at age 3 months, 2 years, 8 years and 15 years. Note similarities with patient in figure 1a, and variation in facial lymphedema. c Lower limb lymphedema in patient 11 at age 3 months, 2 years and 8 years.
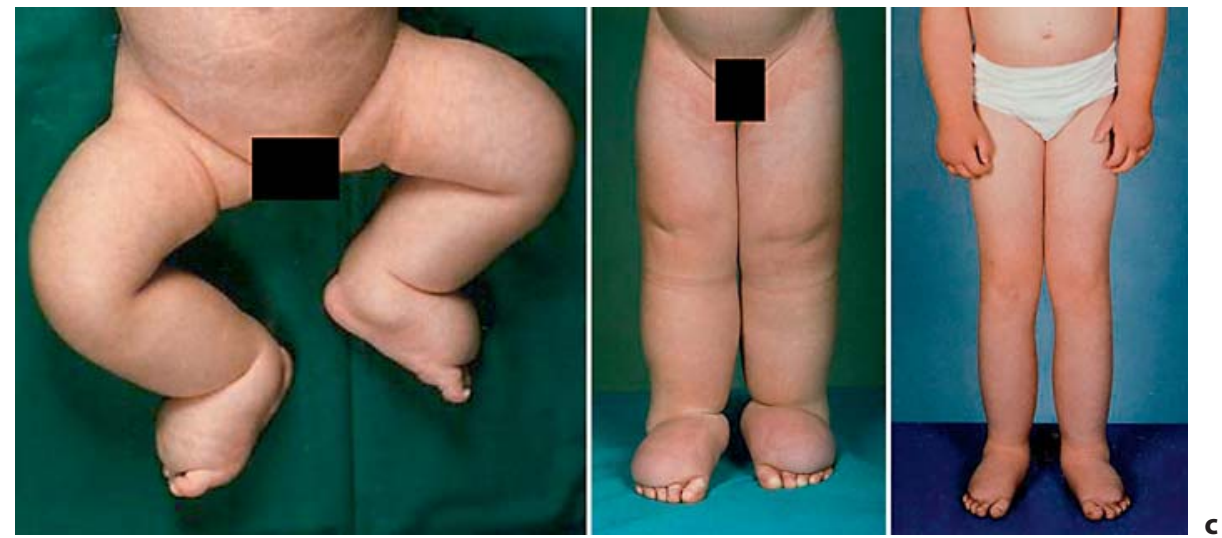

from these patients were obtained from the earlier publication [Alders et al., 2009]. The single patient with a CCBE1 mutation published by another group [Connell et al., 2010] was also added to table 1 as patient 13 to provide a complete literature overview; this patient has also been clinically investigated by one of us (R.C.H.). Clinical data were not available from 16 patients without a CCBE1 mutation.

CCBE1 Mutations in Lymphatic Dysplasia
We divided the group of patients into 3 groups: Group 1: those with a mutation in CCBE1; Group 2: those without a mutation in CCBE1 but in whom the diagnosis HS was considered to be likely and Group 3: patients without a CCBE1 mutation and in whom the clinical diagnosis of HS was considered to be possible but uncertain, or even unlikely, but the referring physician wanted to exclude $C C B E 1$ as the causative gene. In 2 patients, (patient 19 and 
Table 1. Groups according to diagnosis and mutations

a Group 1: diagnosis likely, $C C B E 1$ mutation positive

\begin{tabular}{|c|c|c|c|c|c|c|c|c|c|c|c|c|c|c|}
\hline Patient & 1 & 2 & 3 & $4^{ \pm}$ & $5^{ \pm}$ & 6 & 7 & 8 & 9 & 10 & 11 & 12 & $13^{\$}$ & Total \\
\hline Gender & $\mathrm{m}$ & $\mathrm{m}$ & $\mathrm{m}$ & $\mathrm{f}$ & $\mathrm{m}$ & $\mathrm{f}$ & $\mathrm{m}$ & $\mathrm{m}$ & $\mathrm{f}$ & $\mathrm{m}$ & $\mathrm{f}$ & $\mathrm{f}$ & $\mathrm{f}$ & $7 \mathrm{~m} / 6 \mathrm{f}$ \\
\hline Consanguinity & - & + & + & + & - & + & + & + & + & - & - & - & - & $7 / 13$ \\
\hline Family history positive & - & + & - & - & - & + & - & + & - & - & - & - & + & $4 / 13$ \\
\hline \multirow{2}{*}{$\begin{array}{ll}\text { Mutation CCBE1 } & \text { allele } 1 \\
& \text { allele } 2\end{array}$} & R158C & C102S & C75S & C75S & $\mathrm{C} 174 \mathrm{R}$ & G237R & C75S & C102S & $\mathrm{C} 174 \mathrm{Y}$ & L229fs & C174R & $\mathrm{C} 47 \mathrm{~F}$ & C75S & \multirow[t]{2}{*}{$13 / 13$} \\
\hline & L229fs & C102S & C75S & C75S & L229fs & G237R & C75S & C102S & $\mathrm{C} 174 \mathrm{Y}$ & G271R & L229fs & L229fs & C75S & \\
\hline Age at last investigation & 20 y $(\mathrm{d} 22 \mathrm{y})$ & $17 \mathrm{y}$ & $8 \mathrm{y}$ & $3 y$ & $1 \mathrm{y}$ & 5 y $(\mathrm{d} 6 \mathrm{y})$ & $29 \mathrm{y}$ & $1 \mathrm{y}$ & $2 y$ & $2 y$ & $19 y$ & $20 y$ & $6 y$ & \\
\hline Developmental delay & $\mathrm{DD}$ & $\mathrm{B}$ & $\mathrm{B}$ & - & GMD & $\mathrm{B}$ & - & DD & B & - & B & B & - & $9 / 13$ \\
\hline Growth $<$ P3 & - & + & + & - & - & + & + & + & + & - & + & + & + & $9 / 13$ \\
\hline $\mathrm{OFC}<\mathrm{P} 3$ & - & + & - & - & + & + & - & - & + & - & + & + & - & $6 / 13$ \\
\hline Unusual face & + & + & + & + & + & + & + & + & + & + & + & + & + & $13 / 13$ \\
\hline Lymphedema limbs & + & + & + & + & + & + & + & + & + & + & + & + & + & $13 / 13$ \\
\hline \multicolumn{15}{|l|}{ Lymphangiectasia } \\
\hline Gut & $++^{\mathrm{b}}$ & + & + & + & + & + & + & $++^{\mathrm{b}}$ & + & + & + & + & $++^{\mathrm{b}}$ & $13 / 13$ \\
\hline Lung & + & $?$ & + & + & + & + & + & + & - & - & + & - & + & $9 / 12$ \\
\hline Pericardial & + & + & - & + & - & + & - & + & - & - & - & - & - & $5 / 13$ \\
\hline Kidney & + & $?$ & - & - & $?$ & - & - & - & - & - & - & - & - & $1 / 11$ \\
\hline Genital & + & + & - & - & + & + & + & + & - & $?$ & - & - & + & $7 / 12$ \\
\hline Hydrops & - & - & - & - & + & - & - & - & - & - & + & - & + & $3 / 13$ \\
\hline Heart malformation & - & - & - & VSD & - & - & - & - & - & - & - & ASD & - & $2 / 13$ \\
\hline Blood vessel abnormality & - & - & - & $\mathrm{H}$ & - & + & - & - & - & - & - & TR, AR & - & $3 / 13$ \\
\hline Other & 1 & & 2,3 & & 3 & & 2,4 & 5 & 6,7 & & 8 & & 3 & \\
\hline
\end{tabular}

b Group 2: diagnosis likely, mutation negative

\begin{tabular}{|c|c|c|c|c|c|c|c|c|c|c|c|c|c|c|c|c|c|}
\hline Patient & 14 & 15 & 16 & 17 & 18 & 19 & 20 & 21 & 22 & 23 & 24 & 25 & 26 & 27 & 28 & 29 & Total \\
\hline Gender & $\mathrm{m}$ & $\mathrm{m}$ & $\mathrm{f}$ & $\mathrm{m}$ & $\mathrm{f}$ & $\mathrm{m}$ & $\mathrm{f}$ & $\mathrm{f}$ & $\mathrm{m}$ & $\mathrm{m}$ & $\mathrm{f}$ & $\mathrm{m}$ & $\mathrm{m}$ & $\mathrm{m}$ & $\mathrm{f}$ & $\mathrm{m}$ & $10 \mathrm{~m} / 6 \mathrm{f}$ \\
\hline Consanguinity & + & + & + & + & - & - & + & - & - & - & $?$ & + & + & + & + & - & $9 / 15$ \\
\hline Family history positive & + & - & - & - & - & - & - & - & - & - & - & + & + & + & + & - & $5 / 16$ \\
\hline Mutation $C C B E 1$ & - & - & - & - & - & - & - & - & - & - & - & - & - & - & - & - & $0 / 16$ \\
\hline Age at last investigation & $12 \mathrm{y}$ & $23 y$ & $1 \mathrm{y}$ & $9 y$ & $8 \mathrm{y}$ & $18 \mathrm{y}$ & $4 y$ & $17 y$ & $\begin{array}{l}5 \mathrm{mo} \\
(\mathrm{d} 5 \mathrm{mo})\end{array}$ & $1 y$ & $35 \mathrm{y}$ & $1 \mathrm{y}$ & $40 \mathrm{y}$ & $\begin{array}{l}26 y \\
(\mathrm{~d} 28 \mathrm{y})\end{array}$ & $\begin{array}{l}36 y \\
(\mathrm{~d} 36 \mathrm{y})\end{array}$ & $29 y$ & \\
\hline Developmental delay & - & B & DD & $\mathrm{B}$ & B & sDD & $\mathrm{DD}$ & sDD & $\mathrm{DD}$ & B & - & $\mathrm{DD}$ & B & $\mathrm{B}$ & $\mathrm{sDD}$ & $\mathrm{B}$ & $14 / 16$ \\
\hline Growth $<\mathrm{P} 3$ & + & - & + & + & - & + & - & + & + & - & - & + & + & + & - & + & $10 / 16$ \\
\hline $\mathrm{OFC}<\mathrm{P} 3$ & $?$ & - & $?$ & $?$ & - & - & - & - & + & - & $?$ & - & - & - & + & $?$ & $2 / 11$ \\
\hline Unusual face & + & $\mathrm{a}$ & + & + & + & $\mathrm{a}$ & + & + & + & + & + & + & + & + & + & + & $14 / 16$ \\
\hline $\begin{array}{l}\text { Lymphedema limbs } \\
\text { Lymphangiectasia }\end{array}$ & + & + & + & + & + & + & + & + & - & + & + & + & + & + & + & + & $15 / 16$ \\
\hline Gut & + & - & $?$ & + & + & + & - & + & + & + & + & - & + & + & + & + & $12 / 15$ \\
\hline Lung & - & - & $?$ & + & - & - & - & + & $?$ & + & - & + & + & + & + & + & $8 / 14$ \\
\hline Pericardial & - & + & $?$ & + & - & - & - & $?$ & - & - & - & - & - & - & - & + & $3 / 14$ \\
\hline Kidney & - & - & $?$ & $?$ & - & - & - & $?$ & - & - & - & - & - & - & - & - & $0 / 13$ \\
\hline Genital & - & - & $?$ & + & + & + & - & $?$ & + & + & - & + & + & + & + & + & $10 / 14$ \\
\hline Hydrops & - & - & - & - & - & - & - & - & $+^{\mathrm{C}}$ & - & - & - & - & - & - & - & $1 / 16$ \\
\hline Heart malformation & - & - & - & + & - & - & - & + & PDA & PDA & - & - & - & - & - & - & $4 / 16$ \\
\hline Blood vessel abnormality & - & - & $\mathrm{H}$ & - & - & VP & - & - & - & - & $\begin{array}{l}\text { dup } \\
\text { v.c.i. }\end{array}$ & VP & - & - & - & - & $4 / 16$ \\
\hline Other & 9,10 & & & 10,11 & 10 & 12,13 & 12,14 & $10,12,15$ & 16,17 & 6,10 & & 18 & 17,20 & & & 10 & \\
\hline
\end{tabular}

36) another diagnosis was confirmed cytogenetically (patient 19: $\operatorname{del}(22)(\mathrm{q} 13.3)$ ) or molecularly (patient 36: mutation in PTPN11 confirming Noonan syndrome). Patient 19 was diagnosed as likely HS, and the deletion of chromosome 22q13.3 was identified only after CCBE1 mutation analysis. The patient with Noonan syndrome was known to carry a PTPN11 mutation prior to CCBE1 mutation analysis, but the lymphedema was so marked that it was thought useful to exclude heterozygosity or homo- zygosity for $C C B E 1$ as an explanation for the lymphedema.

We found no CCBE1 mutation in the 158 patients with less marked lymphatic dysplasia, and also no mutation in the 8 patients in whom the clinical diagnosis was considered possible but uncertain. Mutations in $C C B E 1$ were present in a total of 13 patients. Mutations were mostly missense mutations clustered in the collagen domain, the Ca-binding EGF domain or the cysteine rich domain up- 
Table 1 (continued)

c Group 3: diagnosis uncertain or unlikely, mutation negative

\begin{tabular}{|c|c|c|c|c|c|c|c|c|c|}
\hline Patient & 30 & 31 & 32 & 33 & 34 & 35 & 36 & 37 & Total \\
\hline Gender & $\mathrm{f}$ & $\mathrm{m}$ & $\mathrm{f}$ & $\mathrm{f}$ & $\mathrm{f}$ & $\mathrm{f}$ & $\mathrm{m}$ & $\mathrm{f}$ & $2 \mathrm{~m} / 6$ \\
\hline Consanguinity & - & + & - & - & - & - & - & + & $2 / 8$ \\
\hline Family history positive & - & - & - & - & - & - & - & - & $0 / 8$ \\
\hline Mutation $C C B E 1$ & - & - & - & - & - & - & - & - & $0 / 8$ \\
\hline Age at last investigation & $10 \mathrm{mo}(\mathrm{d} 10 \mathrm{mo})$ & $16 y$ & $4.5 \mathrm{y}$ & $16 \mathrm{y}$ & $6 y$ & $8 y$ & $6 \mathrm{mo}(\mathrm{d} 6 \mathrm{mo})$ & $6 y$ & \\
\hline Developmental delay & sDD & - & DD & B & - & DD & $\mathrm{DD}$ & B & $6 / 8$ \\
\hline Growth $<$ P3 & + & + & + & + & - & + & + & - & $6 / 8$ \\
\hline $\mathrm{OFC}<\mathrm{P} 3$ & + & + & + & + & - & + & - & - & $5 / 8$ \\
\hline Unusual face & + & + & + & + & - & + & + & + & $7 / 8$ \\
\hline Lymphedema limbs & + & + & + & mild & + & + & + & + & $8 / 8$ \\
\hline $\begin{array}{l}\text { Lymphangiectasia } \\
\text { Gut }\end{array}$ & + & + & - & + & + & + & - & $t^{\mathrm{b}}$ & $6 / 8$ \\
\hline Lung & + & + & + & - & - & + & - & + & $5 / 8$ \\
\hline Pericardial & + & - & - & - & - & + & - & - & $2 / 8$ \\
\hline Kidney & + & - & - & - & - & - & - & - & $1 / 8$ \\
\hline Genital & - & + & - & - & - & - & - & - & $1 / 8$ \\
\hline Hydrops & - & - & - & - & - & - & - & + & $1 / 8$ \\
\hline Heart malformation & hypoplastic left heart & - & PDA, PFO & ASD & - & - & ASD & aortic stenosis & $5 / 8$ \\
\hline Blood vessel abnormality & - & - & - & - & - & - & - & - & $0 / 8$ \\
\hline Other & 19 & 20,23 & 3,9 & 21 & 22 & 6 & 24 & & \\
\hline
\end{tabular}

+ = Present; - = absent; $\mathrm{mo}=$ month; $\mathrm{y}=$ year; $(\mathrm{d} . .)=$. in case a patient died, age of death; $\mathrm{DD}=$ developmental delay; $\mathrm{SDD}=$ severe developmental delay; $\mathrm{B}=$ borderline developmental delay; $\mathrm{GMD}=$ gross motor delay; $\mathrm{PDA}=$ persis tent ductus arteriosus; $\mathrm{PFO}=$ patent foramen ovale; $\mathrm{ASD}=$ atrial septal defect; VSD = ventricular septal defect; $\mathrm{a}=$ unusual face, but not typical HS; $\mathrm{H}=$ haemangioma; $\mathrm{AR}=$ accessory renal artery; $\mathrm{TR}=$ tortuosity retinal vessels; $\mathrm{VP}=$ difficult to access blood vessels; dup v.c.i. $=$ duplication vena cava inferior.

Other: 1 = Glaucoma; 2 = growth hormone deficiency; 3 = hypothyroidism, $4=$ testis carcinoma; $5=$ diaphragmatic hernia; $6=$ metopic craniosynostosis; $7=$ adrenal neuroblastoma; $8=$ delayed puberty; $9=$ hearing loss, campodactyly with partial cutaneous syndactyly; $10=$ seizures; $11=$ abnormal abdominal situs; 12 = macrocephaly; $13=$ deletion 22q13.3; 14 = brain atrophy, especially vermis atrophy, overgrowth; 15 = agenesis callosal body; 16 = retroperitoneal lymphangioma caudal of the pancreas; 17 = gingival hypertrophy; $18=$ low CD3 and CD4, slightly decreased NK cell function; $19=$ severe vertebral osteoporosis; 20 = scoliosis; 21 = acute lymphatic leukaemia, myopia; 22 = brain heterotopia, aplasia cutis with underneath skull defect; 23 = pectus carinatum; $24=$ molecularly confirmed Noonan syndrome.

${ }^{ \pm}$Patients described in Alders et al. [2009]. \$ Patients described in Connell et al. [2010] and also investigated in person by one of us (R.C.H.). ${ }^{\mathrm{b}}$ Including chylous ascites. ${ }^{\mathrm{c}}$ Hydrops fetalis, improved prenatally.
Fig. 2. Overview of the mutations described in CCBE1. The upper panel represents the 11 exons of the CCBE1 gene; the lower panel represents the CCBE1 protein. Functional domains in the protein (according to Uniprot) and the location of the mutations are indicated.

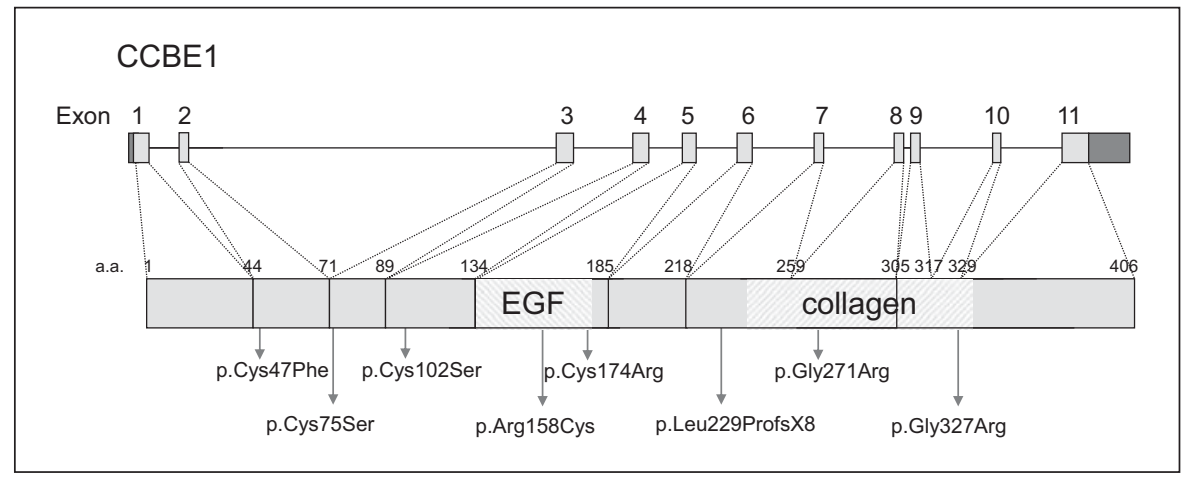

stream of the EGF domain (fig. 2). The mutations in the collagen domain change conserved glycines in the repeating Gly-X-Y motif of the collagen domain and probably affect the stability of the triple helix conformation of the domain. All mutations in the EGF domain and upstream of this domain involve cysteines (cysteines are either mutated or introduced by the mutations), which are crucial amino acids for proper folding of the protein. One recur- rent mutation introducing a frameshift and encoding a truncated protein lacking the collagen domain was found.

We performed statistical analysis on the clinical findings listed in table 1 in the CCBE1 positive and negative patients. No statistically significant differences were present between the patient groups with a clinical diagnosis of HS with and without a CCBE1 mutation. All patients carrying $C C B E 1$ mutations had lymphedema of the limbs, 
unusual face and lymphangiectasia in the gut, representing the most distinctive features of the syndrome. Development varied from normal to severe delay within the group of patients thought to have HS, and indeed this variability is recognised even within a single family [Hennekam et al., 1989]. No difference existed between the patients with a CCBE1 mutation and those without. Growth parameters were disturbed in a similar way in those with and without a CCBE1 mutation, but microcephaly was more common in those with a CCBE1 mutation. Lymphedema and lymphangiectasia were universal in $C C B E 1$ positive patients but less so in those without a mutation. The lymphedema was sufficiently marked at birth to diagnose hydrops foetalis in 3 of the CCBE1 positive cases, in 1 of the CCBE1 negative HS cases and in 1 of the cases thought to have another entity (patient 37). Two CCBE1 positive cases needed respiratory support at night, and 2 other CCBE1 positive cases died in childhood or early adulthood due to respiratory problems. Recurrent chylous ascites was present in 3 molecularly confirmed patients, in none of the unconfirmed patients and in patient 37 (Noonan syndrome). In general there is a tendency for the lymphatic dysplasia to be more marked in the CCBE1 positive patients than in the $C C B E 1$ negative patients.

Seizures did not occur in the group of molecularly confirmed HS patients, but were found in 6 of the HS cases without molecular confirmation. Cardiac anomalies were less common in CCBE1 positive cases than in those without a mutation or with another form of generalised lymphatic dysplasia, and blood vessel anomalies were also more common in CCBE1 negative HS cases. Unusual clinical manifestations in CCBE1 positive patients included metopic craniosynostosis, diaphragmatic hernia, growth hormone deficiency (each occurring in one case), and hypothyroidism ( $\mathrm{n}=3)$. Metopic craniosynostosis was also present in one of the HS cases without a CCBE1 mutation and in a patient from the group with possible HS. One CCBE1 positive case developed a testicular carcinoma in early puberty, and another was found to have an adrenal neuroblastoma in early infancy. One of the patients in the possible HS group had acute lymphatic leukaemia.

\section{Discussion}

In this study, we compared the clinical features of patients diagnosed with HS with and without a mutation in the CCBE1 gene. In addition, a group with less marked lymphatic dysplasia was screened for mutations in CCBE1.
Our results show that $C C B E 1$ mutations are present only in patients with the clinical diagnosis of HS. None of the patients with a possible but less likely diagnosis had mutations in this gene. Two patients had a molecular diagnosis other than HS (22q13.3 deletion; Noonan syndrome). In both patients, the lymphatic dysplasia was very severe, but no additional $C C B E 1$ mutation could be found to explain the severe lymphatic abnormalities in these cases.

In the group of patients with the clinical diagnosis of HS, about $40 \%$ of the patients had CCBE1 mutations. No significant differences were observed between the mutation positive and mutation negative patients with clinically diagnosed HS. All mutation positive patients had lymphedema of the limbs, lymphangiectasia in the gut and the unusual facial morphology considered at least in part being secondary to the intra-uterine facial lymphedema, indicating that absence of these features may correlate with absence of a CCBE1 mutation. The severity of the CCBE1 related lymphedema also is apparent in the need for respiratory support at night in 2 patients and early death due to respiratory insufficiency in 2 other patients. Also, the presence of seizures may correlate with absence of a CCBE1 mutation, as none of the CCBE1 positive patients had seizures whilst several of the $C C B E 1$ negative cases did. Otherwise the patients with and without mutation were remarkably similar, suggesting that other gene(s) involved in HS may well act within the same pathway as CCBE1.

The function of CCBE1 is not completely understood yet. Unlike other lymphangiogenesis associated genes, $C C B E 1$ is not expressed in endothelial cells, but is spatially and temporally expressed along the migration routes of lymphatic endothelial cells and may be a guidance molecule involved in lymphangioblast budding and migration [Hogan et al., 2009]. CCBE1 contains a Cabinding EGF domain. These domains are usually involved in protein-protein interactions, and one might speculate that mutated genes encoding proteins that interact with $C C B E 1$ may also cause HS.

We conclude that $C C B E 1$ mutations cause a widespread and severe form of lymphatic dysplasia, associated with variable intellectual disabilities, unusual facial morphology and infrequently malformations. This indicates it causes a truly syndromic entity. There is no marked clinical difference in patients with and without a CCBE1 mutation, although there is a tendency for the lymphatic dysplasia to be less marked in those without CCBE1 mutations. Further research for the identification of possible other genes causing HS is in progress and will take into account that other causative genes may well act in the same pathway as CCBE1. 


\section{References}

-Alders M, Hogan BM, Gjini E, Salehi F, Al-Gazali $\mathrm{L}$, et al: Mutations in CCBE1 cause generalized lymph vessel dysplasia in humans. Nat Genet 41:1272-1274 (2009).

- Au AC, Hernandez PA, Lieber E, Nadroo AM, Shen YM, et al: Protein tyrosine phosphatase PTPN14 is a regulator of lymphatic function and choanal development in humans. Am J Hum Genet 87:436-444 (2010).

-Connell F, Kalidas K, Ostergaard P, Brice G, Homfray $T$, et al: Linkage and sequence analysis indicate that CCBE1 is mutated in recessively inherited generalised lymphatic dysplasia. Hum Genet 127:231-241 (2010).

-Döffinger R, Smahi A, Bessia C, Geissmann F, Feinberg J, et al: X-linked anhidrotic ectodermal dysplasia with immunodeficiency is caused by impaired NF-kappaB signaling. Nat Genet 27:277-285 (2001).

- Fang J, Dagenais SL, Erickson RP, Arlt MF, Glynn MW, et al: Mutations in FOXC2 $(M F H-1)$, a forkhead family transcription factor, are responsible for the hereditary lymphedema-distichiasis syndrome. Am J Hum Genet 67:1382-1388 (2000).

-Ferrell RE, Baty CJ, Kimak MA, Karlsson JM, Lawrence EC, et al: GJC2 missense mutations cause human lymphedema. Am J Hum Genet 86:943-948 (2010).
Ghalamkarpour A, Holnthoner W, Saharinen P, Boon LM, Mulliken JB, et al: Recessive primary congenital lymphoedema caused by a VEGFR3 mutation. J Med Genet 46:399-404 (2009).

Hennekam RC, Geerdink RA, Hamel BC, Hennekam FA, Kraus P, et al: Autosomal recessive intestinal lymphangiectasia and lymphedema, with facial anomalies and mental retardation. Am J Med Genet 34:593-600 (1989).

Hennekam RC, Krantz ID, Allanson JE: 2010. Gorlin's Syndromes of the Head and Neck, ed 5 (Oxford University Press Inc, New York 2010).

Hogan BM, Bos FL, Bussmann J, Witte M, Chi NC, et al: Ccbe1 is required for embryonic lymphangiogenesis and venous sprouting. Nat Genet 41:396-398 (2009).

Irrthum A, Karkkainen MJ, Devriendt K, Alitalo $\mathrm{K}$, Vikkula M: Congenital hereditary lymphedema caused by a mutation that inactivates VEGFR3 tyrosine kinase. Am J Hum Genet 67:295-301 (2000).

-Irrthum A, Devriendt K, Chitayat D, Matthijs G, Glade C, et al: Mutations in the transcription factor gene SOX18 underlie recessive and dominant forms of hypotrichosis-lymphedema-telangiectasia. Am J Hum Genet 72: 1470-1478 (2003).
Karkkainen MJ, Ferrell RE, Lawrence EC, Kimak MA, Levinson KL, et al: Missense mutations interfere with VEGFR-3 signalling in primary lymphoedema. Nat Genet 25:153159 (2000).

- Ostergaard P, Simpson MA, Brice G, Mansour S, Connell FC, et al: Rapid identification of mutations in GJC2 in primary lymphoedema using whole exome sequencing combined with linkage analysis with delineation of the phenotype. J Med Genet 48:251-255 (2011).

artaglia M, Mehler EL, Goldberg R, Zampino G, Brunner HG, et al: Mutations in PTPN11, encoding the protein tyrosine phosphatase SHP-2, cause Noonan syndrome. Nat Genet 29:465-468 (2001).

-Van Balkom ID, Alders M, Allanson J, Bellini C, Frank U, et al: Lymphedema-lymphangiectasia-mental retardation (Hennekam) syndrome: a review. Am J Med Genet 112:412421 (2002).

Van Schaftingen E, Jaeken J: Phosphomannomutase deficiency is a cause of carbohydratedeficient glycoprotein syndrome type I. FEBS Lett 377:318-320 (1995). 